\title{
LIV. The measurement of high specific resistances
}

\section{R. Threlfall M.A.}

To cite this article: R. Threlfall M.A. (1889) LIV. The measurement of high specific resistances, Philosophical Magazine Series 5, 28:175, 452-468, DOI: 10.1080/14786448908619891

To link to this article: http://dx.doi.org/10.1080/14786448908619891

$$
\text { 曲 Published online: } 08 \text { May } 2009 .
$$

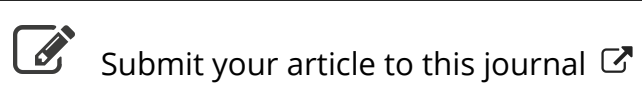

\footnotetext{
山 Article views: 2
}

Q View related articles ¿ 
IIV. The Measurement of High Specific Resistances. By R. Threlfali, M.A., Professor of Physics, University of Sydney, N.S.W.*

[Plate XIV. fig. 3.]

THE experiments which form the subject of this paper were begun almost immediately after my arrival in New South Wales, in June 1886, and have been continued at intervals ever since. The original object was to measure accurately the resistance of certain gums produced by trees growing in the Colony. The only gum thoroughly examined however, up to now, is that produced by the "grass tree" (Xanthorrhoea hastilis). This gum, in spite of many attempts to improve it by various methods of purification and by mixing with other substances, turns out to be useless as an insulator, having in fact no higher resistance than, say, ordinary samples of resin, that is about $4.1 \times 10^{3}$ megohms per cubic centimetre. Besides this, the gum in question is faulty in other ways. It is of the nature of shellac, but cannot compete with the shellac as ordinarily supplied either in price or purity. In addition it has the two fatal defects of being partly soluble in water and of decomposing before it melts. Long-continued gentle heating does not seem to improve it in this latter respect; while the texture of the material becomes looser, it grows friable and very dark in colour. Benzoic acid appears to be given off in large quantities during the process. In spite of many attempts I have hitberto failed to obtain any considerable quantity of the fig-tree gums which are said to be produced in large quantity in the northern parts of the Colony. This paper therefore will be devoted to a description of the method adopted in measuring these resistances, a method which ultimately reached a considerable degree of perfection; partly on account of the modifications introduced in the construction of high-resistance galvanometers, and partly on account of the peculiar property of Clark cells. The method has since been empioyed for other measurements, as will be shown later on.

I do not wish to claim any superiority for the galvanometer over the electrometer methods, except that, given the galvanometer and cells, it is certainly more easily applied, especially when the determinations are numerous. I was forced to adopt the galvanometer method in this instance through not having an electrometer ; but I was by no means

* Communicated by the Physical Society: read March 23, 1889. 
unwilling to do so, because $I$ have long been of the opinion that the galvanometer as usually constructed is susceptible of considerable improvement for delicate work by simply pushing the ordinary conditions of sensitiveness nearer to their limit.

\section{General Description of Method.}

\section{Measurement of Resistance of Gums.}

The substance to be tested forms a layer of very exactly estimable dimensions between two plates of conducting material. The experiment consists in obtaining equal deflexions of a sensitive galvanometer-(1) when a known fraction of the E.M.F. of a Clark cell is allowed to act through a megohm in the galvanometer circuit; and (2) when the E.M.F. of a known number of compared Clark cells is allowed to act through the resistance to be measured.

'The apparatus, therefore, consists of the plates with the substance to be investigated, the galvanometer, the standard cells, and a megohm.

\section{The Resistance-plate Arrangement.}

This consists of two brass plates accurately rectangular and scraped flat on one surface. The dimensions of the plates I used were-length $15 \cdot 2$ centimetres, breadth $12 \cdot 7$ centim., thickness 1.6 centim. These rather exact numbers were obtained by filing. The measurements were made $(\alpha)$ by beam compasses, $(\beta)$ by the dividing-engine. Neither the corrections which had to be introduced for temperature nor the comparison of the dividing-engine scale and the beam compasses with the standard metre are given, as no absolute measurements of pure substances have been made. Several measurements of each plate were made by both methods. The surfaces were made flat by scraping, and this process was continued till the contact was sufficiently perfect for one plate to lift the other when laid on it, both surfaces being clean in the ordinary sense. The upper plate is furnished with a solid handle something like the handle of a flat-iron, and is pierced by three holes, through which pass the micrometer distance screws (see Plate XIV.). The screws are 4 centim. long, and the threaded portion is 55 centim. in diameter (they would have been better if twice the diameter). The micrometerheads are divided into a hundred parts each, and the mean pitch of the screw, as determined by a comparison with the millimetres of a standard scale by means of a measuring microscope, is 39.5 divisions to a millimetre; that is, one turn is equal to 5063 millimetre at $20^{\circ} \mathrm{C}$. The points of the 
screws are conical, and the distance from the end of the thread to the point of the screw is 5 centim. The screws are of steel tempered to the blue, the heads of brass; and the tap used to produce a thread in the holes through the brass plate was identical with one of the screws; the lathe being set to use the same part of its screw and of its change wheels during the making of each; the measurement showed that the screws were very good especially in the middle portion; they were also practically exactly alike. The goodness of the fit in the brass plate was shown by the fact that an increase of temperature of $20^{\circ} \mathrm{C}$. was sufficient to "bind" the screws very perceptibly. Indices similar to the indices of spherometers were erected in the upper plate of the apparatus-one index for each screw. All the workmanship being accomplished, the plates were next platinated by a process given in Gore's 'Electro-metallurgy' under the name of "Roseleur's Process;" a previous experiment showed that when the directions are faithfully carried out, this process will yield a hard bright deposit of platinum. The bath, however, is vory troublesome to keep in order since no solution of platinum takes place to supply the place of that deposited. To prepare the plates for platinating, they were first heated to the temperature of boiling water and rubbed on the scraped surfaces with a solution of caustic potash. Finally, they were rubbed with a bit of fine pumice dipped in dilute caustic potash. This is by far the best laboratory method known to me for preparing surfaces of brass for electro-plating; a clean surface is obtained with comparatively little abrasion. Before I found this out, I was much troubled to secure a good deposit. After platinating, care being of course taken to prevent the deposit being unequal, the plates were carefully washed and dried. It was noticed that the metallic surfaces were covered with a faint bloom of black platinum. On placing the plates together and moving the top one slightly, the lower plate at once adhered, and though weighing several pounds could easily be lifted by the upper one. On pulling the plates apart the "bloom" was found to be burnished practically all over both surfaces, showing of course that the platinating had not sensibly altered the planeness of the surfaces. For this accuracy I am much indebted to the university assistant, Mr. James Cook, who, being accustomed to preprare optically flat surfaces, was led by the application of experience gained in that way to the happy result above mentioned.

The exact position of the two plates with respect to one another was secured by cementing the plated surfaces together with hard paraffin. Two lugs of thick brass were 
made fast by screws to each plate, and brought as near to one another as consistent with leaving an air insulating space between them. These were then bored to fit slightly conical steady pins. A rim was also screwed round the lower plate, so that when the top plate was removed the bottom plate resembled a tray. The rim projected about $\cdot 8$ of a centimetre on each side of the surface, and extended to a height of about half a centimetre above it.

The gum was introduced between the plates in the following way. The micrometer-screws were carefully cleaned and screwed through their holes till they made contact with the lower plate; the point of contact was almost as easy to estimate as in the ordinary use of the spherometer. At all events three or four consecutive attempts to fix the point of contact did not differ from each other by more than about one half of one of the micrometer-divisions. The accuracy with which the contact-point can be fixed depends mainly on the workmanship of the screw, which must fit perfectly "tight and free," to use the mechanic's very expressive term. The contact-points having been found, they were permanently scratched on the micrometer-heads and called zero points. The next operation consisted in screwing each of the screws through a known number of turns. In one experiment this amounted to making the distance of the plates apart $=.02$ centim.; and in another the distance was reduced to 01 centim. with equally good results. It is not advisable in any absolute measure to reduce the distance to much less than this, because the error of the micrometer, depending as it does (as in this case) chiefly on the small irregularities of the screw, must not be allowed to become sensible. There is no doubt, however, that with first-rate appliances the micrometers might be easily made a hundredfold as accurate as mine, and their travel actually measured in situ by a suitable reading-microscope. In this case it would be important to make the screw portion much thicker to avoid any risk of permanent distortion (twisting) when the screws are finally screwed back while partly held by the gum*.

The screws being adjusted, the plates are slowly heated in a gas-oven till some gum laid on the surface of the lower one is in a state of quiet fusion. The great object is to avoid any distortion of the plates. With this aim in view the plates described were cast about twice as thick as they finally required to be in order that the "shell," supposed to be in a

* Since this was written an improvement of the above micrometerscrew has been devised, entirely getting rid of the difficulty here referred to.-Oct. 3, 1889 . 
different state of strain to the interior, might be approximately remoyed. The plates were planed first on one side and then on the other till the right quantity of metal was removed; the last cuts being taken very fine. The handle affixed to the upper plate was of course arranged so as to fit loosely, and not in any way constrain the free expansion and contraction of the plates; the temperature having been often violently changed (by heating for cement \&c.), it is hoped that the plates may be considered fairly well annealed. There is no doubt, however, that for complete satisfaction in an absolute measurement the plates should be capable of being optically examined during the process of heating. This would require to be done in the gas-oven or other uniform field of temperature and at the time the experiments were made. I had not the requisite appliances.

It was found by several trials that the best way of obtaining a layer of gum free from bubbles between the plates, was to float the lower plate or tray pretty full of gum, and also to obtain a layer of gum free from bubbles and in quiet fusion on the upper plate. In the case of the grass-tree gum this could only be obtained by heating the gum for some time at a temperature higher than the one at which it was when the plates were brought together. This was accomplished much in the same way as is sometimes done in microscopy-when the cover-slip is placed on the slide with one edge down and the other end gradually lowered. The freedom irom bubbles of the layer of gum obtained in this way was tested by allowing the plates to cool, and then heating the lower one till its surface reached the temperature of the melting-point of the gum, the upper one being kept cool. This being done the upper plate could finally be lifted, leaving only a small portion of the gum on the lower plate-owing to the small beat-conductivity of the gum. The layer of gum was left thick on one occasion for the purpose of this test, and when the manipulation described above was properly carried out there were no bubbles; the layer in fact was very homogeneous indeed. The only danger left so far as the insulating material is concerned is that it may tend to crack away from the plates during cooling. In the cases examined this did not seem to be the case, because in the first place a thick layer of the same substance rapidly cooled on a thin plate showed no tendency to crack. Again, a great many insulating substances are more or less plastic, or rather viscous, down to temperatures very nearly approaching those at which experiments are usually made (in this country $23^{\circ} \mathrm{C}$. is a not unusual temperature). Again, the massiveness of the plates being 
considerable no distortion of them ought to be caused by the gum, if the ordinary precaution of allowing them to cool slowly be observed.

In the experiments hitherto made the cooling took place during the night in the gas-oven, which being coated with non-conducting material took a long time to cool. On the other hand, in all experiments of the sort one is in a dilemma. If the substance is placed between conducting-plates there are dangers of the kind mentioned; if, on the other hand, the material itself be worked with a view to making it take a prescribed form, the difficulties, especially in the measurement of its thickness, become great. I began by making some attempts of this kind, using blacklead to make the gum-surface conducting, and plating this electrolytically. The difficulties arising in the shaping of the plates are, however, practically prohibitive with friable material. Besides this I have often noticed that in electrotyping it is difficult to prevent the deposit being "spotty" at first, and this has shaken my faith in the perfect continuity of ordinary blacklead surfaces. Possibly platinating with an induction-coil may be really the best way.

However, to finish the description of the case in point :The gum was carefully scraped away from the edges of the plates as soon as they were cool, and the screws were screwed back. This could not be done with any ease at first because of the cementing action of the gum. This was got over by heating the head of the screw with a Bunsen flame : finally, the screws were retracted far enough to be quite out of the way*. A correction to the area of surface has of course to be made for the three screw-holes. If the thickness of the gum be considerable compared with the diameter of the hole, this may be very complicated. In the present case it was negligible. Thus the whole area of the gum-plate was 193.04 centim. less the area of the three screw-holes $-\cdot 7128$ centim., i.e. 192:3272.

Now it is elear that, owing to the curvature of the lines of flow round the edges of the holes, the real correction will be less than the one made. The deposit of gum, however, is pierced by a hole corresponding to the conical end of the screw and, consequently, only very small.

* Note, Dec. 1888.-The difficulty is, however, serious, and has led to new hollow screws being made. Through the holes bored down the centres of the screws gold-plated copper rods pass; these are pinned to the screws till it is required to retract them; the ends of the screws themselves are flush with the lower surface of the upper plate, or very near so. 
Finally, the steady pins are taken out of the plates and the gum is ready to be measured.

In order to measure the resistance of good insulation by means of this arrangement, it is clear that it will be advantageous to have a galvanometer of the highest degree of sensitiveness. This is desirable both because the thicker the insulating layer the less will be the experimental error in the determination of its thickness; and the smaller the electromotive force required the less will be the difficulty of estimating it exactly, as will be shown in the proper place. I therefore attempted to obtain sensitiveness by pushing the ordinary conditions further than is usually done. My first experiments were on a galvanometer of about $9000 \mathrm{ohms}$ resistance, made by the Cambridge Scientific Instrument Company. It was soon very evident that when the current reached the value of about $10^{-7}$ ampere, the torsion of the suspension became important. My first modification was to increase the length of the fibre to about 12 inches; this led to considerable difficulty of adjustment, but increased the sensitiveness about fifty-fold. It then became clear that the next step must bo to get the magnets more perfectly astatic and to reduce the weight of the mirror. The reducing of the weight of the mirror turned out to be more difficult than I anticipated; however, it was finally arrived at, and at the same time the astaticism was made more perfect. Some experiments showed that it was very difficult to get two sets of steel bars of the kind ordinarily employed even reasonably astatic. The difficulty lies partly in the magnetizing and partly in obtaining exactly equal quantities of steel in the two systems of magnets. In fact it is necessary that the steel bars be magnetized in situ, otherwise they can hardly be perfectly arranged and are sure to demagnetize each other more or less. Now when the two magnet systems are only separated by a bit of aluminium, say three inches long, it is impossible to thoroughly magnetize one system without demagnetizing the other more or less. Consequently it is necessary to set up an arrangement so that both systems can be magnetized at once. The following is a description of the arrangement adopted :- It consists of two small electromagnets with extremely soft cores, and movable pole-pieces most carefully worked so as to fit the ends of the cores. Every precaution was taken to make the electromagnets as much alike as possible; the iron was cut off the same rod, it was bent to the same templet, the annealing of both cores was done in a box of asbestos at the same time. The four brass bobbins 
carrying the wire were also made as much alike as possible, and the same number of turns of wire were put on each bobbin by means of a revolution-counter. The winding was quite uniform, No. 18 B.W.G. wire being used. As a check the resistances of the bobbins were measured, when it fortunately happened that two were about one half per cent. higher than the other two, and so they were paired. The wire, it need hardly be added, was wound on to the four coils under a constant strain. The two electromagnets were then mounted on a permanent stand-one being kept steadily in a fixed position, and the other being capable of sliding parallel to a line drawn perpendicular to the lines joining the centres of the poles of each magnet. The polepieces were bevelled off from the top side; but the area of the ends remained large compared with the size of the magnets to be magnetized. The condition as to equality of quantity and quality of steel in the galvanometer magnets was next considered. After some reflexion I decided that the most probable way of securing equality would be to discard bar-magnets entirely and use disk-magnets. I therefore procured a small piece of sheet steel about as thick as ordinary thin writing-paper, and had a die constructed so as to stamp small disks from this sheet. The sheet was fairly hard, and it was found that the disks "stamped" better when the sheet was taken in its natural state than when it was softened. A considerable number of disks were stamped out of the sheet, and these were then laid on a bit of flat iron and raised together to a bright red heat; they were then plunged together into a jar of cold water. On examination they all seemed to be glass-hard, and some of them remained flat. The four flattest ones were chosen and prepared for mounting. A bit of aluminium wire was cut to the right length and beaten out flat at each end. The disks were then cemented with shellac varnish, one on each side of each flattened end of the aluminium wire. The wire was thus much more accurately the centre of rotation of the magnetic system than is generally the case. Attempts were then made to get a good light mirror. About three ounces of small microscope coverslips were examined by aid of the reflected image of the bars of a window, and from these about twenty were selected and silvered by the Rochelle salt process. They looked very good, but on mounting for trial without strain they all turned out disappointing. I finally made use of a small portion of a larger mirror that had got broken. This was cemented on to the flat surface of one of the steel disks and was found not to be sensibly distorted. After trying very many cements, I 
incline to think that nothing is better than a trace of slowdrying white paint. Amongst other experiments I tried cementing two very thin glass disks together, selected so as to mutually correct each other by the drying of the cement. I also tried a method of using plaster of Paris. As plaster of Paris expands on setting I covered the back of a thin mirror with a layer of it about $\frac{1}{12}$ in. in thickness on drying, this of course forced the mirror into a concave form. The back of the plaster was rubbed away on a fine file till it was only about $\frac{1}{20}$ in. thick, and the mirror still remained very concave. Since cementing magnets on to disks with shellac varnish invariably forces the mirror to become convex, I hoped that I should obtain a correction of the concavity produced by the plaster by the convexity which the shellac tends to provoke. My anticipation was completely realized; the mirror on examination turned out all that conld be desired, but, alas, was too heavy for the purpose for which I required it. I can, however, most strongly recommend the process to anybody who desires a mirror to be flat and does not mind it being heavy. 'The best way is to use very little plaster and then to leave the mirror concave. This concavity can be removed by painting on small successive films of shellac; it must be remembered that shellac films go on contracting for several days after they cease to be sticky. Equally good results can of course be obtained by cutting out (with a rotating tube and emery) disks of the size required from previously examined thin sheet glass. The surfaces generally require regrinding. The advantage of the process described is that it onables thin cover-slip glass, which is generally to hand, to be kept flat.

The mirror having been mounted on the steel disks, these last were magnetized by the apparatus mentioned above. In carrying out this operation the following precautions have to be observed:-

1. The distance between the pole-pieces requires to be the same for each magnet. This was attained by setting them to touch a carefully prepared brass rectangular bar.

2. To annul the effect of any small outstanding differences between the cores of the magnets the current was supplied to them in multiple arc, and was strong enough to magnetize the cores beyond the saturation point.

The approximate moment of inertia of the magnet system was easily calculaterl, and it was found that the astaticism was at least ten times as good as the best $I$ had been able to obtain with small bar-magnets mounted on mirrors or mica, and magnetized with a small horseshoe magnet. Of course, 
as has been pointed out by several observers, there is danger of rapid variation of the magnetization; but it was thought better to risk this than to force it by artificial "ageing " by heating or otherwise. As will be seen hereafter, the magnets were never exposed even during the experiments to anything but the smallest electromagnetic forces, and the controlling magnet was weakened and introduced from high above the galvanometer, and only lowered sufficiently just to make its influence on the combination really felt. This is a delicate operation with ordinary arrangements, but becomes simple when the construction of the galvanometer is modified in a way to be explained directly. If one desires to keep the astaticism perfect, it is necessary to be mindful not to use the controlling magnet so as to produce demagnetization ; nor must the currents through the galvanometer ever rise to much greater values than those corresponding to the effects to be observed. From an examination of the investigation in Maxwell, vol, ii. articles 437 and 438 , both $\mathrm{Mr}$. Adair and I came to the conclusion that the disk form of magnet would retain its magnetization pretty well. This has turned out to be the case, for after more than a year's hard use, for all sorts of purposes, the galvanometer has still a sensitiveness of about one division for $10^{-9}$ ampere. The galvanometer is in daily use for testing cells with a view to their application to the resistance measurements at present under discussion.

This galvanometer, however, never came to be relied on to measure currents of less than $10^{-8}$ to $10^{-9}$ ampere. In the course of reading on the subject I consulted the paper by Messrs. T. and A. Gray in the Proc. Roy. Soc. 1884, vol. xxxvi. p. 287. These gentlemen made use of a new arrangement of magnets and coils, which, however, can hardly be understood without referring to the picture, loc. cit. The coils and magnets were so arranged that the poles of the magnets were normally situated in conical holes containing the axes of the coils. The two horseshoe nagnets were suspended from a frame of aluminium wire by one or two silk fibres of considerable length. The coils themselves were composed of very fine wire and had a high resistance. I lost three months' hard work in making and testing this arrangement, which certainly has the advaintage of being practically perfectly astatic. The suspended arrangement being rather large was most troublesome to mount and balance, and had the additional disadvantage of having so great a moment of inertia that its period of vibration often amounted to 70 or 80 seconds. This sluggishness had the property of making it most difficult Phil. Mag. S. 5. Vol. 28. No. 175. Dec. 1889. $2 \mathrm{M}$ 
to use, for it was hardly possible to distinguish the motion due to the electromagnetic forces from the never-ceasing motion due to air-currents. Though the instrument was wellprotected by a glass case, and this generally supplemented by a wooden box, I never succeeded in eliminating the effect of air-currents, though it must be added I never succeeded well enough with it in other respects to make it worth while to apply the "subjective" method of mirror observation. In any case it seems to be essential to have a means of adjusting the coils to the magnets as well as the magnets to the coils; but the adjustments are very tiresome even with the facilities which in the later forms of this instrument I had for making them. My coils had not quite so much wire as those of the Messrs. Gray because I used all I had and could get no more in Australia. However, the aggregate number of turns amounted to 59,900 , and the resistance at $20^{\circ} \mathrm{C}$. was 15,852 B.A. units as against 62,939 turns, and a resistance of 30,220 ohms attained by the authors quoted. The authors also state that the wire was approximately uniformly distributed throughout their coils, though in my case this was found impossible, keeping the external dimensions quite constant, and therefore there was a slight difference between the coils, which, however, was compensated for by their arrangement in the instrument. I do not think that the diminution of the number of turns had much effect, because the diameter of the coils had reached 5.8 centim. Feeling that my non-success was probably to be traced to my inferior skill as an experimentalist, I undertook a long series of trials with a view to discovering the best way of hardening the magnets and their best position in the coils when at rest; amongst other experiments the following will do for description. Three bits of Stubb's steel wire were carefully cut and filed to a uniform length of $4 \frac{1}{16}$ in., their diameters being $\frac{3}{64}$ in. These will be called A, B, and C. A was made glass-hard throughout; B was hardened through a distance of from $\frac{3}{4}$ to 1 inch at each end ; $\mathrm{C}$ was hardened from a distance of from ${ }_{8}^{1}$ to $\frac{1}{4}$ inch at each end. These bits of wire were then magnetized by being placed between the massive poles of a very large electromagnet. The cores of this magnet were 3 inches in diameter and about 25 inches long. The pole-pieces were very broad and thick. The magnetization of the steel was carried nearly to saturation, and the magnets were found by filings to be free from consequent poles. On taking the times of vibration the following numbers were obtained :- 
A made 25 vibrations in 125 seconds.

$\begin{array}{llll}\text { B } \quad " \quad, & 124 \quad, \\ \text { C } \quad " & 105 \quad,\end{array}$

After remagnetizing the magnets with about half as much current again round the electromagnet, it was found that

A made 25 vibrations in 123 seconds.

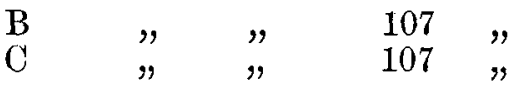

$\mathrm{B}$ therefore was improved; $\mathrm{A}$ and $\mathrm{C}$ remaining about the same. The deviations were probably produced by the unavoidable shaking and jarring in mounting the magnets, though this was done with considerable care.

These magnets were next observed with respect to their behaviour with one of the coils. Coil "No. 3 " was selected for this purpose. It was placed on the table, and above it hung a specially fine spring-coil of wire forming part of a Jolly's balance. The magnets were hung from the end of this spring by a loop of silk, and could be adjusted to penetrate the coil to a greater or less extent. In general five positions were taken :-

Position 1. Magnet-end flush with the upper windings of the coil.

2. Magnet-end at $\frac{1}{4}$ of the length of the hole through the coil.

3. Magnet-end at the centre of the coil.

4. Magnet-end at $\frac{3}{4}$ of the length of the hole through the coil.

5. Magnet-end flush with the bottom of the coil.

Three Leclanché cells were allowed to run for four hours through the coil before the experiment began. The coil had a resistance of 3130 ohms.

First, a series of observations was taken by observing on the glass scale the equilibrium position of the magnet with the current direct and reversed. The magnet was then lowered to position 2, and so on; then it was reversed and the experiments repeated. Two complete sets each way were made for each magnet, $i$. e. forty observations of distance and forty reversals of current. The experiment was a very pretty one, and I never remember to have seen any apparatus work better. The following set is given as a sample from the notebook. The numbers, of course, bave no significance except with respect to the actual coil and magnet taken. 
Magnet B.

Position in Coil.

At edge of coil $\frac{1}{4}$ way in $\frac{4}{2}$ way in $:$ : $:$. : : Near" $\dot{\frac{3}{4}} \dot{0} \dot{0} \cdot \dot{\cdot}$ $\left(\frac{1}{8}\right.$ inch off)
Double displacement with current + and - . .43 centim. $\cdot 77$ $1.03 \%$ $1 \cdot 159$, 1.04 "
Number of experiments. 3

Magnet B reversed, otherwise everything the same.

\begin{tabular}{|c|c|c|c|c|c|c|}
\hline \multicolumn{2}{|c|}{ Position. } & \multicolumn{4}{|c|}{$\begin{array}{c}\text { Displacement current } \\
+ \text { and }- \text {. }\end{array}$} & \multirow{2}{*}{$\begin{array}{c}\text { Number of } \\
\text { experiments } \\
2\end{array}$} \\
\hline t. edge & • & & & $\cdot 415$ & centim. & \\
\hline way in & - & & & $\cdot 78$ & , & 2 \\
\hline " & • & • & - & • & " & \\
\hline off' bo & om & 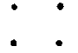 & & $1 \cdot 11$ & " & 2 \\
\hline
\end{tabular}

The nett result was that all the magnets behaved best when they started from three quarters to the whole way in, and that B was best, C almost as good as B, and A distinctly the worst. On reducing the observations it turned out that the ratio of the mean displacements of $A$ and $B$ was about $\cdot 782$, while the ratios of the magnetic moments was $\cdot 755$. This relation is of about the order one would expect, seeing that the length of the magnets was about $9 \cdot 6$ centim. and the dimensions of the coil were :- axial $3 \cdot 8$ centim., radial at one end $2 \cdot 4$, radial at other end $2 \cdot 5$. The external surfaces of the coils were cylindrical.

The ratio of the greatest displacements was $\cdot 643$. It may be conceded, therefore, that the questions of magnetization and placing received a fairly complete answer. In the final arrangement of the galvanometer with horseshoe magnets, like those described by the Messrs. Gray, the lengths of the yokes of the magnets was 8.5 centim., and thus this was the distance between the centres of the coils. The legs of the magnets were 3.8 centim. long, and they were magnetized like the trial magnet $\mathrm{B}$. When in position, the magnet-legs projected into the coils to an extent of about $?$ the axial dimension of the latter. The suspension was two washed silk fibres (one would not carry the load) 16 centim. long.

The test for sensitiveness was made by running a large Clark cell (already described) through 10,000 legal ohms, and a certain small resistance taken out of an ordinary Bridge-box. The terminals of the Bridge-box were coupled up through the 
galvanometer to a megohm. The accuracy of this method of testing has been already established.

The distance from the galvanometer-mirror to the scale was 155 centimetres; and the light-spot was very good, showing the wire image as sharply as the lines on the scale. The scale itself was divided into millimetres. In the final test the period of vibration of the magnet system was 80 seconds, and the resistance out of the Bridge-box was 100 ohms. The E.M.F. acting through the megohm and galvanometer and $100 \mathrm{ohms}$ was therefore $\frac{100}{10100}$ (lark cells, say $\cdot 0145$ volt. The current was therefore $\frac{\cdot 0145}{116000}=1 \cdot 26 \times 10^{-7}$ amperes.

Employing the method of vibrations and neglecting the correction for the extremely small log. decrement, the battery being of course reversed and several experiments made, it was found that the double deflexion amounted to 5 scale-divisions (millims.). Hence the deflexion corresponding to $1.26 \times 10^{-7}$ amperes is 2.5 divisions. Now I do not think that, bearing in mind the lengthy period of the system, it would be possible to read to more than 5 division. The difficulty comes in in eliminating air-currents ; as far as the scale went I could read certainly $\cdot 2$ division, so there is no advantage to be gained in having the scale further, or even so far away. We may therefore say that five times the least measurable deflexion is given by $1 \cdot 26 \times 10^{-7}$ amperes, or that the least measurable deflexion itself is given by $2 \cdot 5 \times 10^{-8}$ amperes. This, I may mention, is only to be obtained when the magnets are judiciously kept from swinging by an extra controlling magnet, worked carefully from a distance till the vibrations get small, so as to jam against the side of the coil. Some fine quartz threads were also prepared by Boys' method, but no appreciable improvement introduced by their use could be detected. This may, however, have been on account of their thickness ; for they could be seen, with a little practice, in a good light, and when laid on a bit of black silk. I therefore came to the conclusion that neither I nor my instrumentmaker (who is fairly good) could hope to compete in such delicate work with the Messrs. Gray, who, using this type of galvanometer, attained a sensitiveness of one half millimetredivision with a current of about $10^{-11}$ amperes, and that with a scale fairly close to the instrument, and with a manageable period of vibration.

In consequence of this failure I determined to use the four coils constructed for the Gray galvanometer, for an expe- 
riment in which they were employed in the usual manner. They were therefore roughly mounted, and provided with an astatic combination of the kind previously described. The results were so encouraging that the same methods were pursued further. In the final form the suspension was a quartz fibre, 85 centim. long, suspended in a carefully chosen glass tube. With such long suspensions the tube must be very straight, and the arrangement for raising and lowering the suspended parts must be very good. After trying several arrangements for this, I adopted a pointed piston working into the tube and passing through a stuffing-box. The coils were of course anything but suited, as far as shape goes, for their present arrangement; however, they did what was requisite, though I have no doubt that coils might be made to increase the sensitiveness tenfold.

The mirror was in this case suspended midway between the magnets, and, for want of a better, was so thin that it got a little pulled out of shape by the paint which was used to fasten it to the aluminium wire. This fortunately turned out to be an advantage in some respects, for the vertical wire and the paint on the back of the mirror, by a happy accident, made the figure of the mirror practically that of a portion of a cylinder with a vertical axis; consequently, using a very good lens of 40 inches' focus, a good image of the light-spot was obtained at a distance of three metres. It became evident at once that the two real difficulties in securing sensitiveness lay in preventing air-currents and in adjusting the controlling magnet.

The first was finally attained by making the instrument practically air-tight; and, by means of a diaphragm, stopping down the beam of light to very nearly the size of the mirror -in this case of about 1 centimetre diameter. During the measurement of the resistance of an impure sample of sulphur this protection against air-currents was found to be insufficient, and the galvanometer was further protected by enclosing it in a cardboard box. If it ever becomes necessary to make an instrument to be sensitive to, say, $10^{-13}$ amperes, I shall have the support for the controlling magnet absolutely independent of the galvanometer-case, so that any vibrations set up in adjusting the magnet shall be transmitted only through heavy masonry. In the galvanometer now being described the controlling magnet could be raised by a nut and screw combination, itself sliding on a brass tube attached to the case of the instrument. The glass tube containing the fibre was clamped at its upper end to a very heavy stand of brass and lead, and this practically sufficed when the sensitiveness got to be of the order of one division to $10^{-11}$ amperes. 
The arrangement for adjusting the distance of the controlling magnet was arrived at after several trials. It consisted of an apparatus sliding and clamping on the brass tube, with a nut and screw for fine adjustment. It was intended to use a worm-wheel and screw for the adjustment in a horizontal plane; but this was found after a little practice to be unnecessary, although it would be convenient.

The details of this arrangement for raising and lowering the magnets will be understood from the drawing of the galvanometer for medical purposes on Pl. XIV. figs. 1 and 2 , see p. 416, suprà. Many experiments were made in order to decide the relative merits of quartz and silk fibres. At first it was thought that silk did as well; but after a time a great deal of trouble with the zero was traced to the silk, and attempts were made to use finer quartz threads. In this, owing to the skill acquired by Mr. Pollock, I was finally successful. As I have had about a year's experience in drawing quartz threads, I add the following notes on the process in hope that they may prove of use to others. The difficulty is to get a large enough bit of quartz fused onto a suitable handle. The best way of managing this is first to heat a bit of rock crystal red-hot in an ordinary crucible and keep it heated for about an hour. On cooling, it will be found to have split into fragments of all sizes ; one of these is chosen, and supported on a bit of lime or on a massive bit of iron, and is then fused under the oxyhydrogen (not oxy-coal gas) jet. When it has once been got glass-like it never cracks again, no matter how suddenly it may be heated. Porcellanous quartz draws into rotten threads, as might be expected. Two bits of fused quartz having been prepared they may be fused to the ends of two bits of clay tobacco-pipe, and can then be manipulated in the oxyhydrogen flame without trouble. There is no difficulty (when once the short thick threads have been drawn by hand) in the subsequent shooting. I most cordially indorse all that Mr. Boys says in favour of this admirable invention.

Another difficulty lies in the obtaining of a reasonable degree of astaticism. It has already been shown that it is practically possible to increase the astaticism of a magnetic combination by careful methods of magnetization and manufacture of the magnets: but the astaticism thus in general obtained is by no means perfect. The investigation of this matter was undertaken by Mr. Adair, and proved to be difficult and unsatisfactory. In the first place it was necessary to determine the coefficient of torsion of the silk fibre to be used in the experiments. This fibre was about thirty inches long, and before mounting had been boiled in a tube of water. A copper disk, made up with a mirror so as to have about the 
same weight as nearly as possible as the astatic combination to be examined, was suspended from the fibre in a vibrationbox furnished with a long glass tube. The copper ultimately employed was supposed to be electrolytically pure. The combination at first was slightly diamagnetic, but became much less so as the paint-cement dried, and was finally almost indifferent to any means we could find for testing it. From experiments with this disk, whose weight and moment of inertia were known, the coefficient of torsion of the fibre was found to be $\mathrm{T}=\cdot 000115$ C.G.S., with a load of $\cdot 287 \mathrm{gram}$.

Two astatic combinations were next mounted and tested. The first was the one that had already done some work in the galvanometer, the second was carefully made for the purpose. The moment of inertia of the first was found to be 02126 , and of the second $\cdot 03274$.

With both combinations two sorts of experiments were made. The time of vibration of each was determined, and the change of zero produced by twisting the upper end of the fibre through a known angle, generally $2 \pi$. From these well-known methods it was found that the systems had a period of vibration of about 2.51 seconds only. This corresponded to a value for the moments of the forces of about $\cdot 1270$. The magnitude of this number, as well as the positions taken up by the combinations, showed not only that the astaticism was far from perfect, but also indicated the cause of this: the magnets were not really in one plane. Tentative twisting of the aluminium wires was then resorted to, with the result of bringing up the periods of vibration to 11 and 12.8 seconds respectively. In this latter case the moment was reduced to 0064 . The needle that had been brought to a free period of 11 seconds was mounted in the galvanometer, and by means of the controlling magnet was brought to have a period of 36 seconds, corresponding to a magnetic moment of about 0007 C.G.S. During the experiments on resistance the period was got considerably longer than 35 seconds.

The next paper, on the Resistance of Impure Sulphur, contains the details of the method employed to find both the specific resistance of the gums mentioned and of sulphur. As no useful result is to be expected from a publication of the long series of experimental numbers obtained in the work on Gums, I refer to the following paper for the description of the method employed, since it remained constant throughout. 

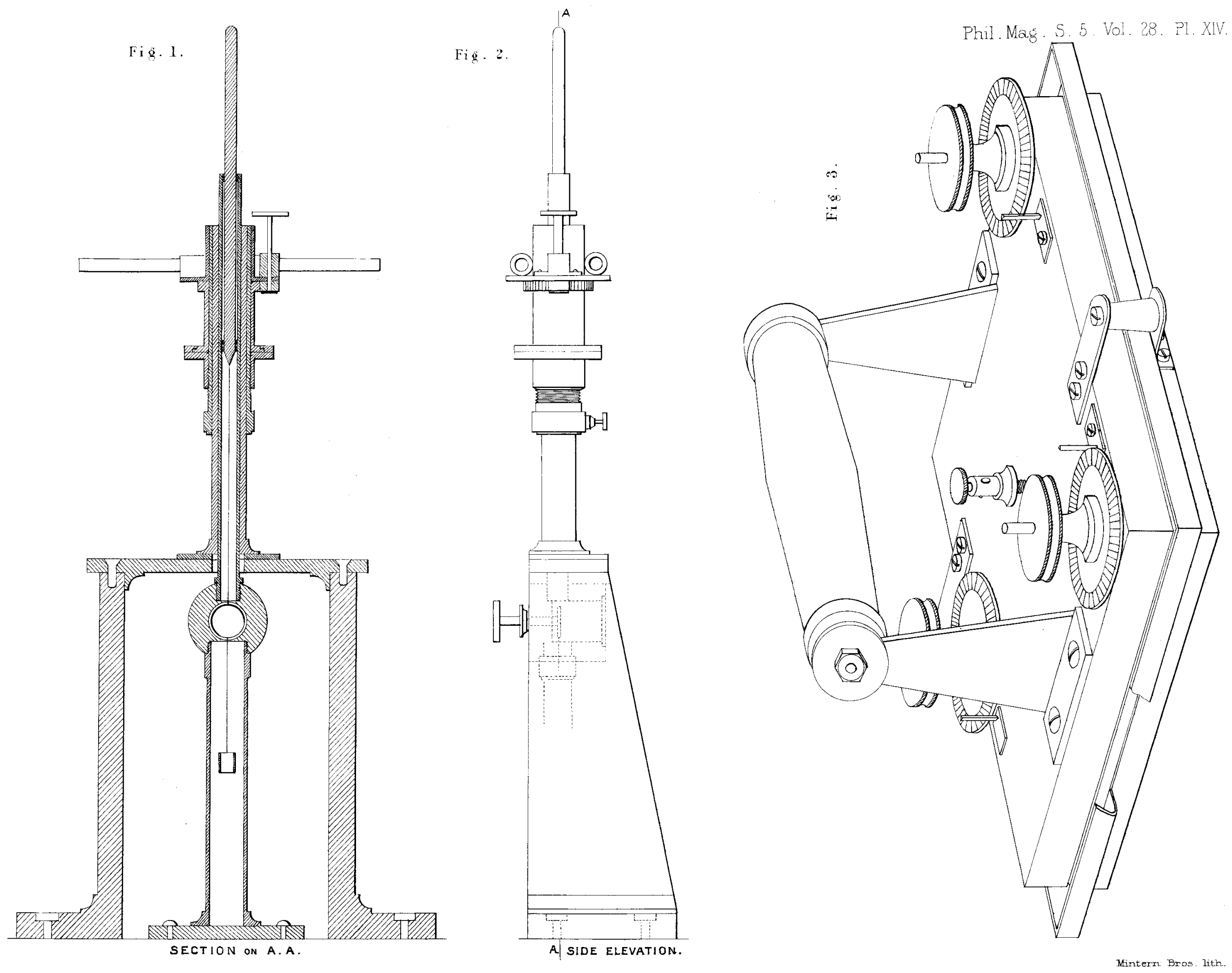